Brit. J. vener. Dis. (1962), 38, 9.

\title{
SEROLOGY OF THE VENEREAL DISEASES*
}

BY

\author{
P. J. L. SEQUEIRA
}

Central Serological Laboratory, Withington Hospital, Manchester

This paper is entitled the serology of the venereal diseases, but it concerns in very large part that of syphilis or, to be more exact, that of the treponematoses and of biological false positive reactions.

Fig. 1, compiled from Ministry of Health statistics for the years 1931 to 1957 , shows the total incidence of syphilis, the incidence of late and latent infections, and the number of deaths notified as due to syphilis. The latter curves follow the trend of other infective diseases and show, with minor irregularities, a steady decline. Deaths from syphilis have dropped from rather more than one-quarter to about one-fifth of the notifications of late symptomatic and latent infections. Superimposed on these steadily

* Paper read to the Manchester Medical Society, October 14, 1959.

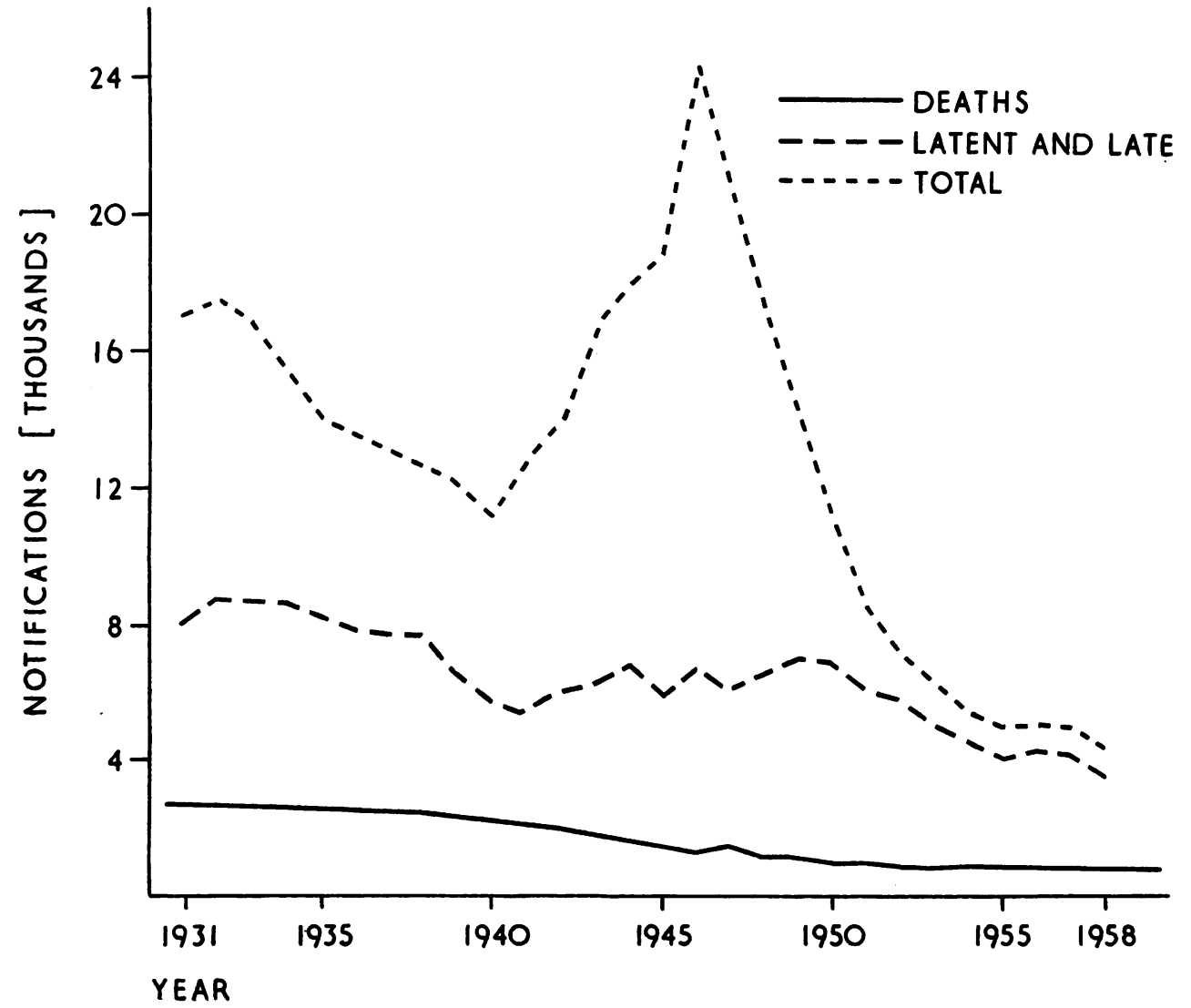

FIG. 1.-Incidence of and mortality from syphilis, England and Wales. 
falling curves is the widely varying incidence of early infections, reaching a maximum in 1946. Before drawing any conclusions from these figures, their limitations must be considered. The notifications of deaths tend to represent a minimum figure, but are probably comparable throughout. The figures for incidence are not, however, comparable, since they include only civilian patients attending V.D. clinics. The very considerable incidence of early syphilis in service personnel in all theatres of the war is almost entirely suppressed, though it is reflected to a certain extent in the steep post-war rise, due in part to the return of these service personnel which was followed by a wider dissemination of infections among the general population. A further complication was the introduction of penicillin. While multiple courses of the arsenicals and bismuth remained the only effective treatment for syphilis, such treatment in general remained the prerogative of the venereologist, whose service provided both the skilled personnel and the continuity necessary for successful control not only of the patients but also of their contacts. The general availability of penicillin provided a relatively simple, safe, and highly effective cure for syphilis. This has resulted in a larger proportion of patients failing to reach the V.D. clinics, which, apart from falsifying the figures represented here, has sometimes resulted in avoidable tragedy through failure to examine a contact in time to avert a lethal or incapacitating lesion, or through over- or under-treatment, often based on a mistaken belief in the infallibility of the serologist. The extent to which the apparent incidence of syphilis has fallen is debatable. A recent study carried out by the British Medical Association Venereologists' Group Committee (1959) in four small but selected areas, which was based on the return of 32 per cent. of questionnaires sent out, indicated that the incidence of syphilis was about 25 per cent. greater than that shown by the official returns. To provide independent data on this problem, and on the incidence of potentially lethal or incapacitating lesions, I have analysed the results of 1,000 consecutive cerebrospinal fluid examinations carried out by my laboratory between July 1 and September 2, 1959. Forty fluids from thirty-nine patients gave positive reactions; ten were from V.D. clinic patients, four of whom were untreated, and thirty were from other sources, nineteen of whom were apparently untreated, and in many of whom syphilis was unsuspected. This large disparity suggests that many such patients are not referred to V.D. clinics and are thus not included in the Ministry of Health figures, and that the incidence of tertiary syphilis, at least of the central nervous system, is greatly underestimated. Such an underestimate would explain the minimal improvement in the death rate from syphilis since the introduction of penicillin which contradicts the clinical findings.

Fig. 2 (opposite) compares the incidence of early syphilis with that of gonorrhoea, the scales being adjusted to align the pre-war curves. The incidence of early syphilis increased proportionately more than that of gonorrhoea during the second world war and reached a maximum of 17,675 in 1946, whereas since that date the fall in incidence has been proportionately greater. This post-war fall at first mirrored the decrease which followed the first world war, and reflected a return to stable social relationships rather than the intervention of the medical profession. The trend has, however, continued, so that in some areas infectious syphilis is no longer endemic, although the importation of infection may result in local, sometimes explosive, outbreaks. The continuing increase in gonorrhoea suggests that the position may deteriorate as in the West Indies where, after a steady rise in frequency of gonorrhoea, the incidence of early syphilis has now also increased.

To summarize, while the notifications of syphilis exceed the average notifications of poliomyelitis, early syphilis is at present relatively uncommon. During the period $1940-1949$, over 100,000 cases of early syphilis were diagnosed among the civilian population, and to these must be added the unpublished number of early infections diagnosed in members of the Forces serving in all theatres of war. A proportion of these patients will have been inadequately treated and so remains at risk. Previous experience suggests that a large proportion of early infections, perhaps a half, may not in fact have been detected, and that these patients may now be entering a period when potentially lethal or incapacitating lesions may occur in about half of those at risk. That these lesions are occurring although the official statistics show no significant rise is suggested by my finding of 4 per cent. Wassermann positive cerebrospinal fluids among those submitted for examination, though only a quarter of these patients were attending V.D. clinics. If the Manchester Regional Hospital Board Area is taken as a representative sample of the population, these figures suggest that the annual incidence of neurosyphilis in Great Britain greatly exceeds the 600 notified cases. We may thus be entering a period when our intervention may save many patients from incapacity or death at a period of their lives when their responsibilities are greatest; with these facts in mind, let us consider to what extent serological methods can be applied to these problems. 


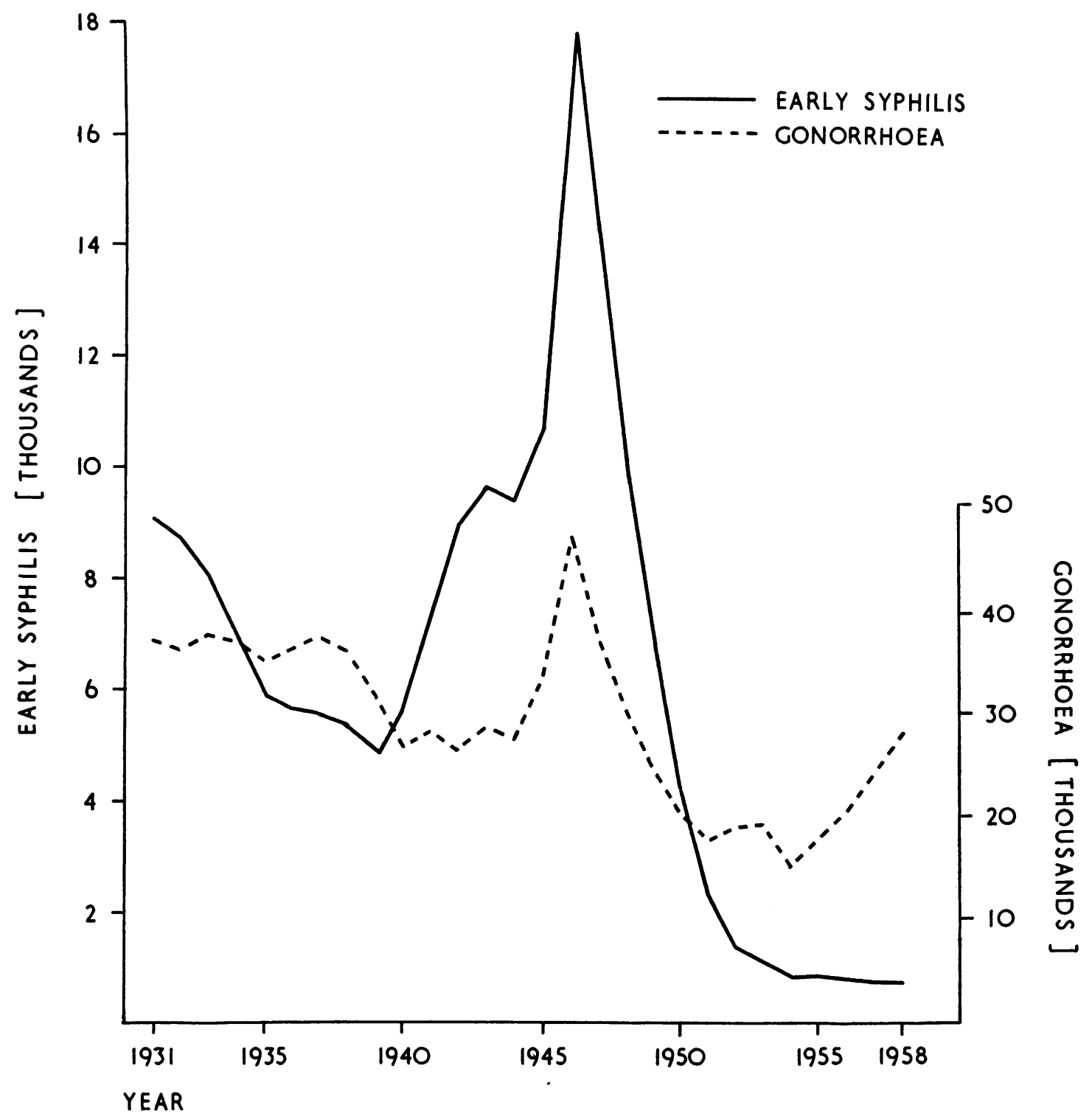

FIG. 2.-Changes in incidence of early syphilis and gonorrhoea.

Serological Methods

Less than a year after the description of Treponema pallidum by Schaudinn and Hoffmann (1905), the first report of the application of the complementfixation test of Bordet and Gengou to the diagnosis of human syphilis (Detre, 1906) appeared in Budapest exactly 2 weeks after the publication of the classical observations of Wassermann, Neisser, and Bruck on the sero-diagnosis of experimental syphilis in monkeys. These workers used antigens consisting of saline extracts of tissues known to contain large numbers of treponemata, and they deemed the antigens of these treponemata to be responsible for the observed specificity of their tests.

Within a year, however, it was found that serviceable antigens for the diagnosis of syphilis could be 
prepared from normal tissues, and within 4 years, antigens derived from alcoholic extracts of heart muscle with added cholesterol were in use; these, with developments and modifications, have remained the basis of the sero-diagnosis of syphilis.

It was soon recognized that these tests occasionally gave positive reactions with the sera of patients in whom the diagnosis of syphilis was excluded; in fact as early as 1911, Bruck contributed a chapter on the false positive reactions of the Wassermann test to a monograph on the pathology and therapy of syphilis (Neisser, 1911).

When these tests were applied to patients in whom the diagnosis of syphilis was likely on clinical grounds, these occasional false positive reactions were of little practical importance. When, however, large numbers of apparently normal people are examined in the course of a programme of mass serum testing, and especially in the routine examination of candidates for marriage and of pregnant women, failure to recognize these reactions as due to causes other than syphilis can have disastrous results.

A biologic false positive (B.F.P.) reaction may be defined as a positive reaction (not due to technical error) given by a serological test for syphilis (S.T.S.) using a lipoidal antigen with the serum of a person not infected with a pathogenic treponema, i.e. in whom the diagnosis of syphilis, yaws, bejel, and pinta are excluded. These reactions may be classified as acute and chronic:

Acute.-These occur during or shortly after an acute infection (frequently of the respiratory tract) and after immunization, and disappear spontaneously after a period of days, weeks, or at the most 6 months. The serological titre is almost always low and there are frequent discrepancies between the results of individual serological tests.

Chronic.-These are characterized by their persistence for months, years, or even for life, and by the absence of any precipitating cause. The titre of the tests, while commonly low, is not infrequently high, and discrepancies between individual tests are not unusual.

Moore (1956), commenting on a personal observation of 148 chronic B.F.P. reactors lasting for periods of up to 20 years, stated that at the time of discovery of the positive S.T.S., two-thirds considered themselves to be in perfect health, while the remainder presented with symptoms which were in general minor and not pertinent to the eventual diagnosis. When disease developed in the patients it tended to follow a uniform pattern of periodic episodes in which arthralgia, arthritis, fever, significant malaise, and psychological disturbances were the most frequent manifestations and bizarre muco-cutaneous lesions, uveitis, serositis, and even severe psychosis were not uncommon. These episodes were separated by periods of remission lasting weeks, months, or even years.

At the time this report was undertaken, among these 148 chronic B.F.P. reactors, ten had developed systemic lupus erythematosus and eight rheumatoid arthritis, while 45 showed clinical and laboratory manifestations which suggested systemic lupus erythematosus as the probable diagnosis. In addition, five had developed serious but bizarre illness in which no definite diagnosis could be made. Thus over 45 per cent. developed serious, or potentially serious, conditions.

When the laboratory differentiation of latent syphilis and B.F.P. reactions was based on the use of lipoidal antigens, it depended on the detection of a difference between the antibodies involved. This problem has been approached in many ways, starting from the chemical fractionation of the antigen, which culminated in the isolation of the immunologically specific substance, cardiolipin, by Pangborn (1941), and including the use of different temperatures and salt concentrations as in Kahn's verification procedures and universal serological reaction (Kahn, 1950), and the inhibition of some reactions by certain serum fractions, as in the Neurath test. These latter tests may distinguish between antibodies in certain electrophoretic fractions, but these differences, while revealing certain trends, are insufficiently constant to be of diagnostic value, and such procedures offer no practical advantage over the carefully standardized conventional tests using either cholesterolized heart extract or cardiolipin antigen.

The specificity of a test may be assessed by the percentage of normal persons whose sera give negative reactions to it. In the assessment of a test, this definition of "normal" presents difficulties as it should be independent of any serological test and therefore involves the careful clinical assessment of 1,000 or more persons. In practice the best that can usually be found is a group in which the incidence of syphilis may be expected to be low, perhaps blood donors or ante-natal patients. Such series may be expected to contain occasional cases of syphilis and therefore 100 per cent. specificity can never be obtained with a series of adequate size unless a bias is introduced by the use of a serological test in the selection of the patients. 
Table I illustrates the percentage of positive reactions which are B.F.Ps, using tests of different specificities in populations with differing incidence of syphilis, a matter of simple arithmetic. It will be seen that a test with a 99 per cent. specificity (which is high for a biological reaction) gives such a high proportion of B.F.P. reactions (even when the incidence of syphilis is as high as ten per 1,000 ) that it is unacceptable as a diagnostic test. With to-day's incidence of syphilis of approximately three per thousand, a test with the extremely high specificity of 99.9 per cent gives about 25 per cent. positive reactions not due to syphilis.

\section{TABLE I}

PERCENTAGE OF ALL POSITIVES WHICH ARE B.F.P. REACTIONS

These percentages depend on the specificity of the tests and the incidence of syphilis. For example, where the incidence of syphilis is 10 per 1,000 and the specificity of the tests is $99 \cdot 5$ per cent.. the expected finding is that, among 100,000 sera, 1,000 positives will be due to syphilis and $(100-99 \cdot 5)$ per cent. $=0 \cdot 5$ per cent. of $99,000=$ 495 will be B.F.P. reactions. Thus the percentage of all positives which are B.F.P. reactions will be:

$$
495
$$

$1,000+495$

\begin{tabular}{c|c|c|c}
\hline $\begin{array}{c}\text { Specificity } \\
\text { of Test } \\
\text { (Per cent.) }\end{array}$ & \multicolumn{2}{|c|}{ Incidence of Syphilis (per 1,000) } \\
\hline $99 \cdot 0$ & 10 & 3 & 1 \\
\hline $99 \cdot 5$ & 50 & 76 & 91 \\
\hline $99 \cdot 9$ & 33 & 62 & 83 \\
\hline 9 & 25 & 50 \\
\hline
\end{tabular}

The problem of the B.F.P. reaction entered an acute phase in the United States in the immediate post-war period, when medical examination on demobilization of the American forces resulted in the discovery of some 100,000 persons with unexplained positive S.T.S.-a rate of about six per thousand.

At that time Nelson was engaged on an investigation into factors affecting the Treponema pallidum survival in vitro. In the course of these investigations, he demonstrated that the serum of patients with syphilis contained an antibody (immobilizing antibody) which rendered living suspensions of treponemata immobile in the presence of complement (Nelson). Table II illustrates the mechanism of a positive reaction. The control column demonstrates survival in the presence of antibody alone. This is necessary to demonstrate that the serum itself is not lethal, perhaps through the presence of antibiotics.

This procedure provided the first satisfactory in vitro test for syphilis using an antigen derived from $T$. pallidum, and is the basis of the treponemal immobilization (T.P.I.) test, which after 10 years is still considered the test of greatest sensitivity and specificity available for the diagnosis of the treponematoses.

TABLE II

MECHANISM OF THE TREPONEMAL IMMOBILIZATION TEST

\begin{tabular}{c|c}
\hline Test & Control \\
\hline $\begin{array}{c}\text { Mobile } \\
\text { Treponemes } \\
\text { Antibody } \\
\text { Complement }\end{array}$ & $\begin{array}{c}\text { Mobile } \\
\text { Treponemes } \\
\text { Antibody }\end{array}$ \\
\hline \multicolumn{2}{|c|}{ Incubate for 18 hours } \\
\hline $\begin{array}{c}\text { Immobile } \\
\text { Treponemes }\end{array}$ & $\begin{array}{c}\text { Mobile } \\
\text { Treponemes }\end{array}$ \\
\hline
\end{tabular}

The technical problems of the T.P.I. test are threefold: first, a living suspension of $T$. pallidum must be prepared; secondly, this suspension must be maintained under conditions ideal for the survival of the treponeme for the test incubation period of 18 hours or more; thirdly, the percentage survival in each tube must be estimated by identifying and counting 25,50 , or 100 organisms under the dark-ground microscope.

The preparation of the suspension demands the maintenance of Nichols' strain $T$. pallidum by the intratesticular inoculation of rabbits. This strain was isolated in 1912 from the cerebrospinal fluid of a patient with neurosyphilis and is still virulent. After an incubation period (dependent on the size of the inoculum, the ambient temperature, and the individual rabbit) a painless orchitis develops. The problem here is to obtain sufficient treponemata before the rabbit produces antibodies and, in practice, the choice of the test day allows an error of no more than one day either way. The animal is killed, and the testes are removed aseptically, sliced, placed in Nelson's survival medium, and gently shaken in an oxygen-free atmosphere until sufficient organisms are extracted, ideally 10 to 15 per microscope field. The maintenance of a high rate of survival (which must, for consistent results, exceed an average of 90 per cent. in the controls) is a matter of meticulous technique in the preparation of glassware, the standardization of reagents, and the maintenance of anaerobiasis.

The limiting factor is perhaps the reading of the test, as this requires skill and considerable concentration for a period of 2, 4 , or even 6 hours for a batch of forty tests or so. After carrying out this test over a period of $6 \frac{1}{2}$ years, I would suggest that no one should try to read more than one batch per week. For this reason and because of the complexity of the test, most operators follow the W.H.O. recommendation and allot priorities, depending on the clinical 
condition; the highest priority is allotted to antenatal patients with positive S.T.S. and no other evidence of syphilis, and all requests not accompanied by adequate clinical information are rejected.

The T.P.I. test is at present carried out in about sixty laboratories throughout the world, and can in no sense be regarded as a routine test. However, its introduction has stimulated serologists to return to Wassermann and Detre's original concept and to use antigens derived from the treponemata. In addition to those which, like the T.P.I. test, use Nichols' strain as the source of antigen, others use cultivable treponemata, usually Reiter's strain. This organism was isolated in 1922, is avirulent, grows in relatively simple media, and survives for long periods of time without subculture. Some authorities consider it to be a saprophyte, others an adapted Treponema pallidum. Table III is constructed to stress the similarity of the antigenic structure of these two strains, and includes the initials of the tests which detect the corresponding antibodies. Each organism contains a lipoidal antigen; this would explain the sensitivity of the S.T.S. but in no way excludes the possibility that, in certain types of disease, special conditions occasionally result in auto-immunization with tissue lipoids, so causing B.F.P. reactions. The postulation of two immunological mechanisms would explain the regular appearance of reagin in the treponematoses and its irregular appearance in conditions known to be associated with B.F.P. reactions.

TABLE III

ANTIGENS OF THE TREPONEMATA

\begin{tabular}{|c|c|c|}
\hline $\begin{array}{l}\text { Nichols } \\
\text { Strain }\end{array}$ & Reiter's Strain & $\begin{array}{l}\text { Antibody } \\
\text { detected by }\end{array}$ \\
\hline Lipoid & $\begin{array}{llll}\text { Lipoid } & \ldots & \ldots & \ldots\end{array}$ & $\begin{array}{l}\text { STS, ?TWR, } \\
\text { TPA }\end{array}$ \\
\hline Thermolabile & Thermolabile (TL) Protein & $\begin{array}{l}\text { TPCF, RCF, } \\
\text { RPCF, ?TPI }\end{array}$ \\
\hline \multirow[t]{2}{*}{ Thermostable } & $\begin{array}{c}\text { Thermostable (TS) Polysac- } \\
\text { charide }\end{array}$ & $\begin{array}{l}\text { RCF, ?TWR } \\
\text { TPA, ?TPI }\end{array}$ \\
\hline & $\begin{array}{c}\text { Organ-specific for brain, } \\
\text { Lipoid }\end{array}$ & \\
\hline
\end{tabular}

In addition, both organisms have heat-labile, probably protein-antigenic fractions, which may be composed of more than one antigen, and heat-stable fractions which may be polysaccharide in nature. The fourth antigen of the Reiter treponeme, described by Witebsky (1929), appears to be something of an immunological curiosity. The best test of the Reiter treponeme series is the Reiter protein complement-fixation (R.P.C.F.) test. The antigen is heat-labile and is prepared by precipitation with ammonium sulphate after the disruption of the organisms by repeated freezing and thawing or by ultrasonics. This test detects an antibody distinct both from immobilizing antibody and from Wassermann reagin. Thus, in terms of practical serology, it is now possible to base the diagnosis of syphilis on the detection of three distinct antibodies. The application of these methods at the Central Serological Laboratory and the interpretation of the results obtained is described below.

The Central Serological Laboratory serves the whole of the Manchester Regional Hospital Board area. During July, August, and September, 1959, an average of 344 sera and cerebrospinal fluids was dealt with on each working day. In the first half of October, 1959, an average of over 420 specimens was examined each working day, by a technical staff of five with seven clerical and ancillary staff. The complement-fixation test used is the Whitechapel Wassermann technique modified (as suggested by Greenbury, 1954) by being carried out on Perspex haemagglutination trays. Three cavities are used for all sera, the upper for the Standard Wassermann reaction, the middle for a cardiolipin Wassermann reaction, and the third for the control. In selected sera and repeat tests, a fourth cavity is used for the R.P.C.F. test. Twenty sera are therefore tested in each tray, and they are identified by placing the tray on a numbered backing, a figure being located behind each cavity. Each tray is marked with a number corresponding to the number of the rack of sera used, and each half of the tray with the first serial number in each row of sera.

Serum is pipetted with a $0.02-\mathrm{ml}$. dropper and saline is added. When the complement titration has been read, the antigens and appropriate complement dilutions are added by two operators using $0 \cdot 1-\mathrm{ml}$. droppers. These operations take about 20 to 30 minutes. The trays are shaken and placed in an incubator for 60 minutes, sensitized cells are then added, and the trays are shaken, replaced in the incubator for 15 minutes, and shaken again.

The tests are read after a further 45 minutes by placing them on the numbered backings used for pipetting the sera. When there is complete lysis, the figure on the backing is clearly visible. Where no lysis has occurred the figure is completely obscured by the button of sedimented cells. Intermediate degrees of lysis are estimated accordingly.

This method of reading may appear rather haphazard, but it is highly reproducible in practice, both between individual operators and from day to day. As compared with the same technique in tubes, it 
shows up minimal lysis more clearly, as the cells are sedimented before reading, but one cannot adjust for errors in the estimation of the complement dose by reading early or late, so that especial care is required with the complement titration.

In addition to the complement-fixation tests, Price's precipitation reaction (P.P.R.) is carried out on all sera. The functions of this tests are to provide a quantitative technique and to act as a technical check. While the change of titre over a period of time may provide information, a high titre, of say 256 dilutions or over, is often found to be associated with aortitis or gumma.

Our testing procedure for cerebrospinal fluids consists in carrying out the two Wassermann reactions and the R.P.C.F. test, and quantitating all positive results. In general, the cerebrospinal fluids of patients with untreated neurosyphilis are positive with all three tests, frequently to a titre of 1 in 16 or higher. Treatment results in a fall in titre, commonly to negative, but sometimes a persistent positive remains in one or more tests. Where the cerebrospinal fluid complement-fixation tests are negative and there is clinical evidence suggestive of neurosyphilis, a T.P.I. test is of more value on the serum than on the cerebrospinal fluid.

The gonococcal complement-fixation test is carried out on request. This test seems of less value than formerly, probably because the majority of patients are treated before they have time to produce antibodies, even when relapses occur. Also low-titre positive results appear to occur in patients without gonococcal infections. Perhaps the greatest signifi- cance of a persistently positive reaction is that it indicates the necessity to review the patient's condition.

Finally, we come to the most important part-the correlation of the clinical and serological findings. I treat a request for a Wassermann reaction as a request for such tests as are relevant to the diagnosis of treponemal infections, and I decide if any further tests are required after considering the patient's clinical condition and the test results.

In order not to complicate the reports more than necessary, only the standard W.R. and P.P.R. are reported on all specimens; the C.W.R. and R.P.C.F. test are reported only when their results are of interest or appear relevant to the diagnosis. Among patients with an established diagnosis of syphilis, the results are reported if they are in general agreement with those previously obtained; any marked discrepancy is checked by re-testing. If a positive reaction is found in a patient who has not been diagnosed or in a patient with negative tests but with the clinical picture suggestive of syphilis, testing is repeated and the R.P.C.F. test is added. If the situation is still not clear, the specimen is retained for the T.P.I. test, or a further specimen is requested if the original is technically unsatisfactory.

The behaviour of the individual tests must be considered before deciding what additional information is obtainable from the different patterns of result. Table IV gives a measure of the sensitivity of the tests, in both untreated and treated patients. The numbers involved are rather small, but they are representative, and all the patients included have been fully assessed with full details of their treatment.

TABLE IV

SENSITIVITY OF INDIVIDUAL TESTS

\begin{tabular}{|c|c|c|c|c|c|c|c|c|}
\hline \multirow{2}{*}{$\frac{\text { Syphilis .. }}{\text { Treatment }}$} & \multirow{2}{*}{$\frac{\ldots}{\cdots}$} & \multirow{2}{*}{$\begin{array}{l}\ldots \\
\cdots \\
\end{array}$} & \multicolumn{3}{|c|}{ Early } & \multicolumn{3}{|c|}{ Late and Latent } \\
\hline & & & Nil & $-I$ year & +1 year & Nil & -1 year & +1 year \\
\hline \multirow{10}{*}{ Test Results } & \multirow{2}{*}{ WR } & + & 6 & 6 & 0 & 33 & 13 & 17 \\
\hline & & - & 3 & 9 & 3 & 9 & 3 & 12 \\
\hline & \multirow{2}{*}{ CWR .. } & + & 9 & 12 & 0 & 42 & 16 & 28 \\
\hline & & - & 0 & 3 & 3 & 0 & 0 & 1 \\
\hline & \multirow{2}{*}{ PPR } & $\div$ & 6 & 3 & 0 & 25 & 9 & 17 \\
\hline & & - & 3 & 12 & 3 & 17 & 7 & 12 \\
\hline & \multirow{2}{*}{ TPI } & + & 8 & 13 & 2 & 42 & 16 & 28 \\
\hline & & - & 1 & 2 & 1 & 1 & 0 & 1 \\
\hline & \multirow{2}{*}{ RPCF . } & $\div$ & 9 & 6 & 0 & 40 & 10 & 23 \\
\hline & & - & 0 & 9 & 3 & 2 & 6 & 6 \\
\hline Totals .. & $\ldots$ & . & 9 & 15 & 3 & 42 & 16 & 29 \\
\hline
\end{tabular}


The first section shows the results obtained with patients with early (primary and secondary) syphilis. "Nil" (totalling nine) indicates untreated patients, and "Less than one year" and "More than one year" (totalling fifteen and three respectively) indicate that treatment was started less or more than one year before the tests shown. The figures in the body of the Table show the number of positives found. The Cardiolipin W.R. and R.P.C.F. test detected all nine untreated patients while the standard Wassermann and P.P.R. detected only six. In this series, the T.P.I. was positive in eight out of nine, which is a rather high proportion as immobilizing antibody appears later than reagin and R.P.C.F. antibody, and is absent in a few patients with early secondary syphilis.

It will be seen that with treatment the results of the tests tend to become negative, and that in the "More than one year" group the T.P.I. is the only test giving any positive results. In a large series, the T.P.I. will be found to be positive in rather more than half the patients with treated early syphilis.

The second section of Table IV illustrates the behaviour of the tests in cases of late and latent symptomatic syphilis. Here there are 42 untreated patients, sixteen treated for less than a year, and 29 treated for more than a year before testing. Among the untreated patients, the Cardiolipin W.R. and T.P.I. test detected all 42 patients, while the R.P.C.F. test was negative in two. Next in sensitivity were the standard W.R. (positive in 33) and the P.P.R. (positive in only 25). The standard W.R. and P.P.R. tended to revert to negative after treatment, while the T.P.I. test and Cardiolipin W.R. became negative in only one (a patient with tabes dorsalis, who had been treated more than 6 years before), and the R.P.C.F. test occupied an intermediate position. The reversal of the S.T.S. appears unrelated to the reversal of the R.P.C.F. test, discrepancies being found with either test positive.

To summarize, the Cardiolipin W.R. is of very high sensitivity at all stages of syphilis, both treated and untreated, while the standard Wassermann is of lower sensitivity and has a greater tendency to revert to negative after treatment. With the exception of early syphilis, the T.P.I. test is positive in all untreated cases, and also, with rare exceptions, in treated cases of late symptomatic syphilis. Where this test is negative, it may be assumed that the patient is no longer infected, and it will frequently be found, on examination of the case notes, that the original diagnosis was not, in fact, firmly established.

The R.P.C.F. test, while more sensitive than the standard W.R. at all stages of syphilis, is less sensitive than the Cardiolipin W.R. in treated syphilis. Occasionally, however, the Cardiolipin W.R. is negative and the R.P.C.F. test positive; in such cases, further examination may reveal evidence of possible neurosyphilis. The routine use of the R.P.C.F. test would bring about a slight increase in sensitivity of the testing programme, but this test is not at present a practical proposition for universal use, though it may become so in the future.

Where one or more reagin tests (S.T.S.) are positive and the R.P.C.F. test is negative, the most likely diagnosis is treated syphilis or a B.F.P. reaction; this pattern of results may be found in perhaps 5 per cent. of patients with syphilis in whom there is no history of treatment and in whom active lesions are occasionally found. In such groups of patients, the T.P.I. test is of most value, as it will distinguish between the B.F.P. reactor and the case of syphilis. The assessment of the need for treatment must rest with the clinician.

Unfortunately, the serological tests now in use do not distinguish between infections due to different species of treponeme, so that it is not possible to distinguish between syphilis and yaws and the immigrant populations in some areas present a considerable diagnostic problem.

Let us now consider the classes of patient to which these serological tests may be applied for diagnosis. In some patients the history or signs make a diagnosis of syphilis possible, probable, or almost certain, or the exclusion of the disease is required in differential diagnosis. These patients require a highly sensitive test and the persistence of positive reactions after the eradication of the infection is most valuable when, for example, a patient presents with an aortic lesion or a disorganized joint.

If such problems are not solved by positive S.T.S. and R.P.C.F. tests, the Cardiolipin W.R. and T.P.I. test will nearly always confirm or virtually exclude the diagnosis.

A variant of this problem is the diagnosis of conditions in which B.F.P. reactions are common. In systemic lupus erythematosis about one-quarter of the patients may have positive S.T.S., and the demonstration that these are in fact B.F.P. reactions may be valuable. In these patients, however, the exclusion or diagnosis of syphilis must be based on the detection of other antibodies by the R.P.C.F. and T.P.I. tests.

We must also aim at the detection of patients with latent syphilis before the development of potentially lethal or incapacitating lesions. These patients can be detected in two ways: 
(1) Directly by routine serological testing. Antenatal tests are the obvious example, but the routine tests carried out by other departments are of great importance as syphilis is a predisposing cause of morbidity. Further examples are the routine serological tests carried out for various civil and public health purposes, though these may be primarily directed to the control of infectious syphilis and the detection of congenital infections.

(2) Contact tracing. I suggest that we are failing if, having cured our patient of syphilis, we allow his spouse to develop general paralysis of the insane.

While the testing programme I have described provides an extremely sensitive means of detecting syphilis, it is at present necessary to test some 300 or 400 persons to find one latent infection, and the specificity of the test system is thus of paramount importance. Table I shows that using a test with a specificity of 99.9 per cent., about a quarter of all positives found would not be due to syphilis under present conditions. Table $\mathrm{V}$ shows the results obtained by testing approximately 900 unselected blood donors. The specificity is expressed as the percentage of positives found, as this is more convenient for some purposes than the percentage of negatives.

TABLE V

SPECIFICITY OF INDIVIDUAL TESTS

\begin{tabular}{|c|c|c|c|c|c|}
\hline \multirow{2}{*}{\multicolumn{2}{|c|}{ Test }} & \multicolumn{2}{|c|}{ Total Positive } & \multicolumn{2}{|c|}{ Positive Alone } \\
\hline & & No. & Per cent. & No. & Per cent. \\
\hline WR. & $\ldots$ & 0 & $<0.1$ & 0 & $<0.1$ \\
\hline CWR. & .. & 9 & $1 \cdot 0$ & 6 & $0 \cdot 7$ \\
\hline $\begin{array}{l}\text { PPR } \\
\text { RPCF. }\end{array}$ & 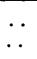 & 2 & $\begin{array}{l}0 \cdot 2 \\
0 \cdot 2\end{array}$ & $\begin{array}{l}1 \\
0\end{array}$ & $\begin{array}{c}0.1 \\
0\end{array}$ \\
\hline TPI & . & 6 & 0.7 & 4 & 0.4 \\
\hline
\end{tabular}

The first section of the Table shows the total positive reactions as a percentage. If we adopt the view that the presence of any two or more of the three antibodies detected by the tests is evidence of present or past syphilis and exclude these from the series, the maximum rate of non-syphilitic reactions is reduced to the figures shown in the second section. As we saw earlier, the T.P.I. test seldom reverts to negative in infections treated after the early stages, thus the finding 0.4 per cent. positives is not surprising in an unselected series. If we adopt the pessimistic view that the proportion of B.F.P. reactions given by the various tests may be as great as shown in the Table, the chance of such reactions occurring together in the same patient will be the product of their incidences. Thus, if we assume that the standard Wassermann reaction gives about one B.F.P. reaction in a thousand tests as can be shown in larger series, and that the R.P.C.F. test gives about one in 500 , these reactions may occur together by chance once in half a million patients. On the other hand, if the Cardiolipin W.R. is positive but not the standard W.R., the chance of error becomes about one in 50,000 . Specificities of the same order will be obtained when the R.P.C.F. test is negative and the T.P.I. test is positive. Thus, basing the diagnosis of syphilis on the detection of at least two distinct antibodies, provides a test system of such exceptionally high specificity that it is possible to raise the sensitivity of selected tests to very high levels without B.F.P. reactions causing any great problem. This test system allows the rapid and confident diagnosis of treponemal infections in the vast majority of patients, and it also allows the differentiation of the remainder from the B.F.P. reactions with equal certainty when the results of the T.P.I. test become available.

\section{Summary}

The notifications of and deaths from syphilis in England and Wales since 1931 are discussed. It is concluded that persons infected during the second world war and its aftermath are now at a stage when they may develop lethal or incapacitating lesions.

The problems and prognostic significance of biologic false positive reactions and the limitations of diagnostic procedures based on the use of lipoidal antigens are considered. It is shown that, even with specificities as high as 99.9 per cent., such tests are not satisfactory when applied to the routine examination of apparently normal persons.

The return to Wassermann's and Detre's original concept of using the antigens of the treponemata and the development of the newer tests is outlined.

The application of certain of these tests to the examination of large numbers of specimens at the Central Serological Laboratory, Manchester, is described, and the characteristics of the individual tests examined.

It is concluded that, where the diagnosis of syphilis is based on the detection of two unrelated antibodies, the overall chance of error is related to the product of the incidences of false positive reactions found with each test and that the resulting specificity is so high that the sensitivity of selected tests can be raised to a very high level without false positive reactions causing a significant problem.

The combination of reagin tests of normal and high sensitivity with the Reiter protein complement- 
fixation Test provides a very sensitive and specific test system of relatively low cost which will detect the majority of cases of untreated treponemal infections. Where discrepancies are found the treponemal immobilization test remains essential to the differentiation of syphilis from biologic false positive reactions.

\section{REFERENCES}

British Medical Association Venereologists' Group Committee in Association with the British Co-operative Clinical Group. (1959). Brit.J. vener. Dis., 35, 111.

Bruck, C. (1911). In "Beitrage zur Pathologie und Therapie der Syphilis", ed. A. Neisser, p. 345. Springer, Berlin.

Detre, L. (1906). Wien. klin. Wschr., 19, 619.

Greenbury, C. L. (1954). J. clin. Path., 7, 73.

Kahn, R. L. (1950). "Serology with Lipid Antigen", Williams and Wilkins, Baltimore.

Moore, J. E. (1956). Brit. J. vener. Dis., 32, 217.

Nelson, R. A., Jr. (1948). Amer. J. Hyg., 48, 120. and Mayer, M. M. (1949). J. exp. Med., 89, 369.

Nichols, H. J., and Hough, W. H. (1913). J. Amer. med. Ass., 60, 108.

Pangborn, M. C. (1941). Proc. Soc. exp. Biol. (N. Y.), 48, 484.

Price, I. N. O. (1950). Brit. J. vener. Dis., 26, 172.

- and Wilkinson, A. E. (1952). Ibid., 28, 16.

Schaudinn, F., and Hoffmann, E. (1905). Arb. Gesundh.Amte. (Berl.), 22, 527.

Sequeira, P. J. L. (1959). Brit. J. vener. Dis., 35, 139.

Wassermann, A. von, Neisser, A., and Bruck, C. (1906). Dtsch. med. Wschr., 32, 745.

Witebsky, E. (1929). Z. Immun.-Forsch., 62, 35.

Sérologie des maladies véniériennes

Résumé

L'auteur discute la notification de la syphilis et les morts qu'elle a causées en Angleterre et au pays de Galles depuis 1931. Il conclut que les personnes infectées pendant la seconde guerre mondiale ou dans la période qui suivit, ont atteint un stade pendant lequel peuvent se développer des lésions mortelles ou pouvant les frapper d'incapacité.

L'auteur considère les problèmes et l'importance pour le pronostic des réactions biologiques positives fausses et les limitations des procédés de diagnostic basés sur l'emploi des antigènes lipoïdiques. Il montre que, même avec des spécificités de $99 \%$, ces tests ne sont pas satisfaisants quand on les applique à l'examen routinier de personnes apparemment normales.

Il expose le retour au concept original de Wassermann et de Detre, lequel consiste à employer les antigènes des tréponèmes, ainsi que le développement de tests plus récents.

Il décrit l'application de certains de ces tests à l'examen de grands nombres de spécimens au Central Serological Laboratory, Manchester, et également les caractéristiques des tests individuels examinés.

Il conclut que, quand le diagnostic de la syphilis est basé sur la détection de deux anticorps sans rapport l'un avec l'autre, la chance d'erreur dépend du produit des incidences des réactions positives fausses de chaque test et que la spécificité résultante est si élevée que la sensitivité des tests choisis peut être très élevée sans que les réactions positives fausses présentent un problème important.

La combinaison des tests par anticorps de sensitivité normale et élevée avec la réaction de fixation du complément par la protéine de Reiter fournit un test très sensible et spécifique et relativement bon marché qui permet de découvrir la majorité des cas d'infections par les tréponèmes non traitées. En cas de contradictions, la réaction d'immobilisation du tréponème reste essentielle à la différentiation de la syphilis et des réactions biologiques positives fausses. 